Ensino, Saúde e Ambiente - V9 (1), pp. 108-121, Abril, 2016.

\title{
EPISTEMOLOGIA RACIONALISTA E ENSINO DE CIÊNCIAS NO CONTEXTO CRÍTICO ATUAL
}

\section{RATIONALIST EPISTEMOLOGY AND SCIENCE EDUCATION IN THE CURRENT CRITICAL CONTEXT}

\author{
Valmir Sbano \\ 1UFF/ Departamento de Psicologia, valmirsbano@uol.com.br
}

\begin{abstract}
RESUMO
No ensino das ciências que praticamos hoje - um ensino coparticipativo, crítico e de valorização dos diversos saberes sociais - há lugar para o aspecto racionalista do empreendimento científico. O racionalismo científico é herdeiro e continuador de uma grande aventura racional iniciada na Grécia Antiga. Na ciência, a razão não se limita a um rigor fiscal exercido a posteriori da percepção e de postulados já dados. As refundações inéditas operadas pela ciência são ações de um plural racionalismo que sempre necessita ser, a um só tempo, educador e aprendiz, formador e formando quanto aos fatos e quanto aos falantes. Mesmo o ensino de ciência não podendo servir de modelo para toda forma de ensino, mesmo a ciência não sendo sua própria empreendedora, pois esta prerrogativa cabe antes aos interesses sociais, a epistemologia da racionalidade científica tem algo a oferecer ao ensino de ciências.
\end{abstract}

Palavras-chave: ensino de ciências, epistemologia, racionalismo.

\section{ABSTRACT}

In the science education practiced these days - a collaborative and critical education, which recognizes different social knowledge - there is room for the rationalist aspect of scientific project. The scientific rationalism is heir and successor of a great rational adventure started at Ancient Greece. In science, the reason is not limited to a fiscal rigidity executed after the perception and the assumptions already established. The original refoundations performed by science are actions of a plural rationalism, which must always be, at the same time, educator and learner, instructor and student regarding both facts and speakers. Even though science education cannot be used as a role model for any type of education, even though science is not its own developer, as such prerogative belongs to social interests, the epistemology of scientific rationality has something to offer to science education.

Key words: science education, epistemology, rationalism 
Qual é o legado racionalista cabível a um ensino crítico, social e participativo das ciências, i.e., ao ensino de ciências que praticamos hoje? Como a epistemologia da racionalidade científica pode nos socorrer na tarefa atual do ensino de ciências?

Foi chamada de "milagre grego" a emergência da Razão na antiguidade grega (VERNANT, 1973). Boa ou má designação para o fato, tal expressão tentou destacar o ineditismo de um discurso que, aparecendo na cidade grega antiga, na pólis, distinguiuse dos demais discursos da sua época, e de todas as épocas anteriores, por não se amparar mais nas certezas dos mitos, e nem se sustentar como mais uma posição opinativa, doxa, na disputa, polemos, da cidade (CHÂTELET, 1972). Aqueles que assistiram pela primeira vez uma tentativa de busca de conhecimento, episteme, pelo uso do raciocínio dedutivo, da razão, sustentada marcadamente por Sócrates, perceberam estar diante de um discurso heterogêneo, novo, com uma visada inédita e autoridade nova. Sócrates nem recorria a autoridade dos mitos, dos deuses, nem emitia novas opiniões na cidade, mas demonstrava (!), com um inédito dizer dedutivo (!), que faltava sustentação racional às opiniões correntes, indistintamente, tradicionais e novas. Isto, demonstrar, deduzir, que não se sabe, quando se pensa que se sabe, era algo inteiramente novo!

Sua condenação à morte (GOTO, 2010), por, supostamente, 1. não reconhecer os deuses, 2. adorar novas divindades (?) e 3. corromper a juventude, atestou à posteridade: 1. o reconhecimento do ineditismo desse novo dizer, e o que ele tinha de chocante por isso; 2. que seus contemporâneos perceberam, ao seu jeito, como a razão socrática se autorizava de um outro princípio; 3. que a razão de Sócrates era um ensino envolvente, um sucesso pedagógico, ainda que, talvez, resultando num fracasso pessoal e político...

Sócrates, que foi um personagem histórico, mas não um autor, tornou-se célebre, principalmente, pelos diálogos de autoria de Platão. E se Sócrates chamava esse seu procedimento de maiêutica, que tem o sentido de parturição, de obstetrícia da verdade e do conhecimento, Platão designou este procedimento de dialética, termo que quer dizer algo como "através do que se diz". Os dois termos tentam chamar a atenção para um traço distintivo desse novo procedimento do dizer, por oposição à doxa mítica ou à doxa polêmica, orto ou heterodoxa. Na maiêutica e na dialética não se trata de acrescentar ao interlocutor, vindo de fora, nenhum termo, nenhuma informação, 
nenhuma asseveração, nada acrescentar de fora ao seu dizer. Trata-se, sim, de extrair dele, desdobrar, do próprio interlocutor, do dizer do próprio interlocutor, o conhecimento, a episteme.

Ou seja, aquilo que depois será chamado de razão já nasceu como uma forma nova de ensino, um ensino que fazia o aprendiz falar, e falar sob uma referência ao mesmo tempo nova e interna ao próprio aprendiz. Paradoxo tipicamente racional, como repetiremos abaixo, entre o novo e o que já está aí nas potências internas do pensamento.

Por exemplo, no diálogo platônico Mênon, Platão nos descreve como, certa vez, Sócrates teria feito um escravo, i.e., um homem não educado como os demais cidadãos livres e senhores da cidade, realizar uma proeza. $\mathrm{O}$ escravo realiza a dedução da incomensurabilidade da diagonal de um quadrado, relativamente aos seus lados (FOWLER, 1987). Procedendo a perguntas que provocam a dedução, Sócrates mostra que o escravo inculto sabe a geometria que o melhor geômetra da Grécia sabia - que pode acompanhar tal demonstração com a mesma experiência de certeza, a mesma intuição pura que o geômetra. Ou seja, ele demonstra que a geometria e a razão se sustentam de demonstração racional, e não de mera adesão a uma crença, a uma opinião, a um pertencimento de grupo, o grupo dos geômetras ou dos homens cultos. A geometria pode ser deduzida, não é um credo, não é uma informação privilegiada, não é o resultado de uma experiência de vida, não é uma senha de grupo. E ele demonstra que a razão, ao encontrar algo, reencontra: já está com o escravo, de algum modo, o saber da geometria. Se ele não o tem por uma educação de fato, ele o tem de direito, já em seu espírito, i.e., na potência intrínseca do seu pensamento. Este é o núcleo reiterado ao longo da história da filosofia idealista e racionalista, como também da história do pensamento científico (KOYRÉ, 1991): no uso da razão, o pensamento vem a saber como quem já sabia; vem a descobrir como quem se redescobre em sua descobertaquando aprende, vê que já sabia; quando ensina, vê-se aprendendo.

Nossas mentes e nossa cultura de século XXI - por séculos alimentadas e habituadas com os produtos da razão, no Direito, na Matemática, na Lógica, na Ciência e na Tecnologia - podem, adormecidas, deixar de se espantar e até mesmo de perceber a emancipação original operada no passado histórico, e que se opera a cada 
vez, pela razão (na matemática, na lógica e, finalmente, na ciência). Como se diz na pilhéria: avô conquistador, pai capitalista, filho consumista e perdulário...

Por exemplo, os princípios da lógica aristotélica, a própria lógica aristotélica, podem passar por triviais, naturais, e, pior ainda, quem sabe, saídos da mera observação do uso da palavra e das argumentações, do mero bom senso, de uma razoabilidade ou lucidez psicológica comum. Ao contrário, a lógica aristotélica, que foi preparada pela dialética platônica, só foi possível por esse inédito manejo racional da palavra, manejo singular, rigoroso, historicamente incomum, quase bizarro - um dizer que não quer primeiramente dizer isso ou aquilo, não quer ter a boa opinião, a opinião certa, a vencedora, mas antes quer descobrir o critério formal, racional, do bem dizer, de um dizer que extrai de si mesmo um conhecimento. A razão que se exprimiu na lógica aristotélica é um singular manejo do dizer; originalidade que se emancipou do uso comum do dizer após milênios de outros manejos do dizer. Vários planetas inteiros de falantes morreram sem suspeitar dela. E esta lógica só foi enriquecida custosamente pelos séculos posteriores. Durante muitos séculos quase que somente nos utilizamos da lógica aristotélica, quase que só gastamos sua riqueza, como o herdeiro perdulário da pilhéria. Pouco contribuímos. Exemplo: a categoria modal da contingência sempre foi confundida, no seio da lógica aristotélica, com a categoria modal da possibilidade. Uma perfeita definição diferencial de contingência e de possibilidade só foi possível no início do século XX, com a introdução da álgebra na lógica (BLANCHÉ \& DUBUCS, 1996).

$\mathrm{Na}$ verdade, não foi e não é somente o hábito que fez e faz a razão desconhecer ou esquecer a originalidade de suas realizações.

Ocorre que, depois dos primeiros passos, passos ainda gregos e greco-romanos, da Matemática, da Lógica e do Direito, o conhecimento "sobre as coisas", o conhecimento físico, ficou por séculos patinando entre a observação empírica e a opinião. E por quê? Justamente por se tratar de conhecimento sobre as coisas que nos cercavam, e não sobre o nosso próprio pensamento. O conhecimento sobre as coisas físicas, que se elaborou com e a partir de Aristóteles, foi um conhecimento organizado, sistematizado, refletido, elaborado, coerente, respeitável, mas jamais intrinsecamente racional, jamais com aquele traço de autoengendramento rigoroso que a dialética platônica mostrou que a Matemática poderia fornecer ao pensamento. E como poderia ser diferente? Afinal, para conhecer "as coisas", a física, não deveríamos partir das 
“coisas", partir da observação, do objeto, quem sabe, no máximo, partir das utilidades das coisas? Não deveríamos, nesse caso, girar em torno do objeto (como expressou Kant), ao contrário de girarmos em torno de nosso intelecto? Em que a matemática poderia nos guiar, nos fazer conhecer, tratando-se de um tal conhecimento sobre coisas da experiência?

Ainda hoje, a epistemologia ingênua, aquela que é a de todo falante antes do estudo epistemológico da história das ciências, nos diz que a ciência, física ou química, é um conhecimento que parte da observação dos fenômenos, e que submete essa observação a um rigor lógico-matemático $a$ posteriori.

Vejam o que diz uma obra universitária de ensino de jornalismo científico, intitulada “o que é a ciência?”. Não se trata de um texto escrito para crianças, apesar de nossa leitura parecer sugerir isso, nem é obra que desconheça certas referências eruditas de história das ciências e de epistemologia. $\mathrm{O}$ que aparentemente não fez diferença. Vejam (os negritos, itálicos e sublinhados de destaque são nossos):

\footnotetext{
"A ciência moderna surgiu no século XVII - durante o período do Iluminismo - e é baseada em fatos observáveis. A ciência compara os fatos com a realidade por meio de experimentos. Por isso, a ciência precisa de laboratórios e ferramentas para estudar tudo, da mais minúscula partícula ao universo inteiro. A ciência estabelece metodologias rigorosas com instrumentos confiáveis para acumular evidências com as quais pode comprovar ou refutar uma hipótese. A ciência avalia suas próprias metodologias e reexamina suas próprias provas. Em condições ideais, a ciência experimental é independente da pessoa que faz a observação ou o experimento. Ela é objetiva e está em concordância com a realidade observada e outros conhecimentos comprovados. A ciência ideal fornece resultados claros, lógicos e isentos de ambiguidade. Sua validade pode ser verificada ou refutada usando argumentos e razão. Resultados científicos devem sobreviver a testes duros e meticulosos. Isso é racionalidade científica. A ciência moderna deduz a verdade a partir de fatos verificados pela experimentação metódica. Experimentos medem as coisas e os fenômenos, dizem quanto pesam, quanto tempo duram, em que direção estão indo etc. Experimentos fornecem informações matemáticas"
}

Certamente, uma beleza de texto comunicativo: desce como água. Nele, a racionalidade científica e a própria matemática só vêm depois dos fatos observados. A racionalidade, o rigor, a lógica e a matemática vêm depois; vêm somente fiscalizar o bem observado, fiscalizar o registro dos fatos, zelar pelo bom tratamento desses dados, fornecidos pela observação e pelos experimentos, compatibilizar esses resultados com os conhecimentos já comprovados; vêm dar rigor e registro depois de eles, os fatos, os dados, emergirem já de uma atenta e meticulosa observação. Racionalidade de escrivão, de contador, de fiscal, de jornalista sério e isento. Racionalidade bedel, correndo atrás 
Ensino, Saúde e Ambiente - V9 (1), pp. 108-121, Abril, 2016.

dos fatos. Nem se desconfia neste texto, que uma racionalidade faça constituir os próprios fatos; nem se desconfia que ela conceba, por conceitos, os fatos a serem conhecidos; que ela dê aos fatos sua própria facticidade, sua própria realidade técnica. Nem se desconfia que a razão possa realizar um recorte inteiramente original e subversivo nas premissas anteriores a ela (e não somente em fatos), fazendo assim emergir fatos que nunca antes tinham se apresentado aos nossos olhos de carne para serem observados - ou fatos que nunca antes tinham sido discriminados como tais.

Vemos o papel dado aos instrumentos e à tecnologia. São eles que ligarão os fatos à racionalidade. Eles é que permitirão fazê-lo, dando exatidão às mensurações, pesagens, delineamento das direções, etc - e tais operações de mensuração e registro, ao lado das meticulosas, zelosas fiscalizações metodológicas, são tomadas como as principais operações cognitivas científicas. Vemos o papel dos experimentos, realizados com tais instrumentos e tecnologia: são eles que darão informações matemáticas.

O liame entre ciência e matemática, no texto lido, só aparece aí ao final: os experimentos darão informações matemáticas. As matemáticas aparecem como informações colhidas, dadas pelos experimentos e seus instrumentos. A razão matemática (do cientista e do aprendiz de ciência) assiste ao aparecimento do resultado matemático (numérico, algébrico ou geométrico) ao fim dos experimentos - ela é passiva como uma expectadora de televisão, de programas de TV realizados pela observação e pela tecnologia dos experimentos.

Nesta concepção, que é sempre a nossa quando repousamos sobre o empirismo e o aspecto externo da ciência, a matemática no máximo (se é que chega a tanto) é uma linguagem de coleta de resultados experimentais; enquanto a epistemologia e a história das ciências convidarão nossa apreciação a vê-la (a matemática) como a mestra ginasta da ciência, sua personal trainer.

O cientista, nesta concepção, é um funcionário de alfândega, na fronteira entre os fatos que chegam do país da realidade pelo portão da observação, carimbando sua entrada no país dos registros claros, lógicos e matemáticos. É quase um contador de ovelhas factuais que passam pela cancela dos instrumentos experimentais, sendo então registradas. 
Até as hipóteses, que são propriamente formulações posteriores e geradas de conceitos, somente são mencionadas após a observação dos fatos e dos experimentos.

Em 2001, pôde-se listar pelo menos 120 artigos, dos 30 anos anteriores, escritos por professores universitários de ensino de ciências, em que esta visão meramente escriturária da racionalidade científica, e de comando empiricista da observação, prevalece na apresentação do que seja fazer ciência (PÉREZ, 2001).

Koyré (1986) nos explicou porque foi tão difícil a aposta socrática e platônica ser feita no terreno da física: nossa percepção, tal como a física de Aristóteles, vê nas coisas e nos fatos físicos uma alteridade para o pensamento. Uma realidade estranha à nossa racionalidade. E uma realidade que se comunica diretamente conosco pelos sentidos, ou não se comunica. Enquanto a aposta da ciência moderna é a mais ousada aposta da razão desde a Grécia. É a aposta de que o real cederá conhecimento na medida em que seja abordado nos termos da razão.

Galileu, logo seguido por Newton, propôs olhar o fenômeno do movimento físico a partir de uma versão ou subversão da realidade que não está dada na realidade que vemos com nossos olhos de carne, ou seja, o espaço geométrico. A aposta racional é a de que um corpo não para seu movimento, é parado pelo atrito, pela resistência do ar, por algo, mas não para... por princípio não para. Ele se comporta realmente, diz a aposta racional, como se estivesse num espaço geométrico, não importa o que meus olhos de carne me digam. E depois de dois compactos séculos de escolarização científica, achamos que vemos o corpo sendo parado pelo atrito, pela resistência do ar mas não o víamos antes dessa matematização da física - só o "vemos" hoje por influência desta matematização difundida pela escola e pela cultura, ainda que essa difusão tenha a marca da precariedade formal.

Demorou, custou muito fazer ver as coisas numa perspectiva ou enquadre concebidos em pensamento, e não recebidos pelos olhos. Um enquadre forçado, portanto, historicamente forçado, forçado para que se pudesse expandir a razão, a dedução e a previsão, para o mundo das coisas, mundo dos objetos, e não das meras ideias. Custou muito convencer o homem que ele podia ser o autor e o ator, digamos assim, do seu conhecimento físico, sobre as coisas, sobre os fatos, que ele não teria que permanentemente padecer, meramente receber esse conhecimento, ou simplesmente atuar como um escrivão meticuloso do que primeiramente recebe perceptivamente, 
como os monges da Idade Média. Na verdade, psicologicamente, nunca estamos plenamente convencidos disso. A epistemologia racional é sempre esquecida pela psicologia realista do dia a dia. E até a cultura e a escola, do dia a dia, passam a esquecer a operação racional que realiza o trabalho científico.

Bachelard (1996), recorrendo à história das ciências, mostrou-nos que, psicológica e historicamente, vemos as coisas guiando nosso olhar sobre elas. Parece que vemos o que vemos porque as coisas estão aí para ser vistas. Parece que nossas ideias são boas porque são verdadeiras e que são verdadeiras porque puderam, desde seu nascimento perceptivo, refletir as coisas, como fazem os espelhos. A iniciativa primeira é a da realidade. Vejo e conheço porque há tal coisa para ver e para conhecer. Chegamos até a acreditar que pela imaginação libertamo-nos dos objetos já vistos, libertamo-nos da percepção. Mas, pensamos aí numa imaginação que sempre parte da percepção, na medida em que foi precedida por ela. Enquanto a ciência proporá que nossa imaginação, que tem um belo papel nas ciências, seja guiada e alce voo a partir da plataforma do pensamento racional formal.

Os fatos científicos, como tais, não existem antes da ciência, e os objetos científicos não são colhidos ou recebidos por nossas percepções ou por ideias imediatamente homogêneas com elas; os fatos científicos e os objetos da ciência não estão presentes nos pensamentos anteriores à formulação conceitual científica, que é, pelo menos relativamente a esses enquadres já dados, uma atividade intelectual original - original porque propriamente racional.

Lembremos de alguns exemplos de fatos que deixaram de exigir nossa observação após a consolidação das descobertas científicas.

Hoje, depois de dois séculos de compacta escolarização científica, feita bem ou mal, depois da instalação de uma cultura de massa atravessada por "referências científicas", quando somos convidados a pensar em "eletricidade na natureza", mencionamos usual e primeiramente os raios, as descargas elétricas atmosféricas.

No século XVIII (BACHELARD, 1996, ps. 29-56), porém, até mesmo 100 anos após a obra de Newton se tornar pública - o que nos faria ingenuamente supor que este espírito matemático tomasse conta das publicações e investigações com pretensões científicas -, ainda era possível ler obras, algumas com a chancela de Academias de 
Ciências, tratando os fenômenos elétricos a partir de percepções muito tradicionais, que hoje, entretanto, podem nos soar bizarras. Um homem culto do século XVIII ainda via a eletricidade como 1) um fenômeno propriamente animista, ligada à vida, 2) uma potência exclusiva de algumas substâncias, 3) inseparável de seu efeito subjetivo em homens e mulheres - dificilmente uma obra falava de eletricidade sem gastar longos capítulos sobre o medo provocado por eles, particularmente em mulheres - e, mesmo, 4) a força por trás dos terremotos. Isso mesmo, para a percepção anterior à difusão da ciência do século XIX, um terremoto era um fenômeno tão ligado à eletricidade quanto um raio, pois ambos causam tremor! Em alguns experimentos científicos relatados em tais obras, comprovava-se essa ligação fenomenológica, fazendo uma corrente elétrica passar por baixo de uma superfície, sobre a qual uma pequena cidade em maquete se alojava. A passagem da eletricidade produzia a queda das casas e edifícios, e via-se nisso uma evidência ou indício de confirmação do que já se percebia.

Como se praticavam, neste cenário, guiado pela percepção, os experimentos sobre eletricidade? Dando choque elétrico em filas de pessoas. Nada mais natural, já que eletricidade era concebida, porque percebida, como vivacidade, o tremor da vida! Este termo, vivacidade, em algumas obras era proposto como seu sinônimo. Como o choque elétrico seria transmitido em uma cadeia de homens e mulheres? Experimentos. E... em uma cadeia de eunucos? Experimento!

Não são obras e experimentos produzidos por lunáticos, por "primitivos", por excluídos da escola e localizados nas periferias do mundo desinformado. Não. São obras e experimentos produzidos no coração da Europa, por homens cultos, que se creem cientistas porque fazem experimentos conformes ao saber homogêneo às percepções. E que já tinham lido Newton e o Iluminismo, além, é claro, de Aristóteles, São Tomás, etc.

São obras da percepção. E de ideias já guardadas, por hábito e amor a ideias cotidianas.

Nossa percepção nos sugere, com aquela irresistível força indutiva que ela e as fáceis ideias compartilhadas têm sobre nós, que: A) o sistema decimal existe porque temos dez dedos - enquanto a fundamentação da matemática nos ensina que contamos sucessivamente a partir do zero, o que faria do 9 o décimo número natural (ALVARADO, 2006); B) a vida, uma espécie de "força" ou "energia", é responsável 
pelas organizações biológicas; é algo que anima por dentro a carcaça de cada organismo; é o que há em comum entre uma minhoca e uma águia - enquanto a biologia darwiniana nos diz que elas compartilham sim uma história evolutiva, desdobrada pelo jogo de mutações ao acaso e da seleção natural, únicos fatores últimos responsáveis pelas organizações biológicas; C) alguma substância flogística combustível de uma peça está por trás da queima desta peça (os de Química sabem o que estou mencionando aqui), enquanto Lavoisier introduziu o oxigênio e o conceito de sistema fechado; D) Etc.

Não é, repetimos esta nuance, somente nossa percepção que faz obstáculo a essa aposta de racionalidade realizada pela operação intelectual científica. Todo saber já sabido, também o faz. E inclusive o saber científico depositado em memória, em obra já feita. De modo que a inquietude racionalista da ciência vale como uma nova inquietude socrática: por quais interrogações racionais podemos questionar o bem fundado saber que já sabemos, inclusive do saber científico que já sabemos? Se não se tratava de pôr Newton por terra, poderia se tratar de relativizá-lo? Se não se tratava de pôr Euclides por terra, poderia se tratar de abrir espaços não-euclidianos variando um dos seus axiomas?

A história recente da ciência, de Newton aos nossos dias, mostrou que a razão ela própria pode e deve se reinventar; pode se recriar e não tem nunca de si mesma uma orquestração central e total (ao contrário do que pensava Kant - BLANCHÉ, 1967). Mas a aposta da ciência, da modernidade à contemporaneidade, continua a ser que, abordado racionalmente, tomado pelo pensamento formal, o real cede conhecimento. $\mathrm{E}$ o vetor inverso, se é que existe, não produz o mesmo.

A aposta racional da(s) ciência(s) é, então, tripla:

1. Se há razão aqui, haverá lá e alhures; se há razão, haverá fenômeno (Mendeleev, guiado pelo formalismo "grego" da tabela periódica, prevê elementos químicos que ainda não tinham sido descobertos empiricamente (CARUSO \& OGURI, 2006); Einstein sendo confirmado por experimentos posteriores a sua morte; etc);

2.O real nos cederá conhecimento, se interrogado, manejado, abordado, demarcado, reperspectivado pela razão; 
3. Para a razão, aposentadoria não é um direito; descansar é morrer; as próprias conquistas científicas transformam-se em obstáculos epistemológicos; sua inteligibilidade precisa se metamorfosear para continuar fecunda;

E, epistemologicamente falando, o vínculo da racionalidade científica com o ensino de ciências é íntimo. A ciência, podemos dizê-lo após tudo o que foi dito, ensina formalismo e estrutura aos fenômenos. Galileu ensinou aos corpos a relatividade do movimento. Já dizia Sócrates que não sabe quem não sabe ensinar o que sabe (e, obviamente, estava falando assim do saber racional, pois há saberes outros que podemos perfeitamente saber sem saber ensiná-los).

A racionalidade científica tem uma relação íntima inclusive com o ensino coparticipativo. Pois, ensinando aos fenômenos como eles devem se constituir, aprende em seguida com eles ao se apresentarem - eis o empirismo douto da ciência, como bem o diria Bachelard. Aprendendo com seus fenômenos, a ciência aprende ao "formar", e com seus "formandos".

A racionalidade da ciência ensina, socraticamente, ao cientista e ao aprendiz de ciência que estes precisam desaprender sua segurança de já cientes; que estes, quando ensinam de memória (repetindo o que guardam na memória) a si mesmos ou a outrem, são professores preguiçosos e autoritários; que, ao contrário, quando reanimam a atividade intelectual racional, única que é realmente senhora do que diz, porque não o diz por mero capricho do querer e do acreditar (seja o querer e o acreditar individual ou o de grupo), protagonizam eles um ensino que convida a novos protagonismos de ensino.

O ensino das ciências, à luz do racionalismo científico, inspira-se no ensino das matemáticas, assim como a ciência tomou a matemática como sua inspiração. Um ensino (o de matemática) em que o aluno não recebe informações, não é convidado a "guardar coisinhas na cabeça", mas realiza junto com o professor as operações; junto ou até adiante do professor, antecipando-as. A razão não tem dono, não é a vitória de ninguém, na mesma medida em que pode ser a de qualquer um. Inclusive do escravo.

Porém, grande porém, talvez, por isso mesmo, jamais haverá ciência para tudo; pois... a história parece nos dizer que há e haverá, irremediavelmente, o querer e o 
Ensino, Saúde e Ambiente - V9 (1), pp. 108-121, Abril, 2016.

acreditar de indivíduos e grupos, que há e haverá vencidos e vencedores. E, por isso, talvez, ao menos, devamos considerar que o ensino de ciências não pode servir de modelo para os demais ensinos. E que, reciprocamente, talvez haja peculiaridades próprias ao ensino de ciências que o distinguem dos demais ensinos.

O ensino de línguas, de literaturas, de música, de história, de filosofia, entre outros, não são ensinos menos importantes do que o ensino de ciências - tal afirmação dispensa demonstração. $\mathrm{E}$, certamente, não têm as mesmas relações com a epistemologia científica. Por exemplo, levar a noção de ruptura epistemológica com o já sabido para o seio de outros ensinos, por exemplo, o ensino gramatical da língua, não nos pode nortear em nada, nem em relação ao que romper, nem em favor do que romper (a gramática não é e nem pretende ser uma ciência), resultando nesse caso muito mais em uma desqualificação do falante espontâneo (e do aluno, então) em nome de uma suposta "ruptura epistemológica" (inadequadamente importada a contexto que não lhe é própria); absurdo educativo e até linguístico, pois o falante espontâneo, qualquer falante, é, quanto a sua língua, o juiz de última instância, o STF da língua (MARTINET, 1975).

E tais ensinos não são menos importantes também porque o próprio trabalho da ciência não se faz em um platônico Mundo de Ideias, mas no mundo de disputas, polemos, históricas e sociais. Essas disputas e decisões e interesses polêmicos, nesse sentido etimológico da palavra, ou simplesmente interesses sociais, podem se utilizar da ciência e dar uma direção ao trabalho científico. E devemos dizer bem mais do que apenas que tais interesses "se utilizam" da ciência: são os interesses sociais que, concretamente, empreendem a ciência. A ciência, justamente por ser uma obra racional, cada vez mais é feita através do diálogo ou trocas no interior de uma imensa comunidade científica, que, como qualquer comunidade, requer infraestruturas socioeconômicas para se organizar, que a política dispõe para ela ou não dispõe, dispõe para certas pesquisas e não para outras.

Embora não seja difícil entender este papel precedente dos interesses sociais no empreendimento da ciência (muito menos difícil do que entender o papel da razão na realização da ciência), certamente pode ser bem difícil tolerar, aceitar e sustentar as consequências éticas de seu descortinamento. Enfim, sem abrir outra discussão, cabe aqui simplesmente assinalar que o aspecto racional da ciência não é o único que 
comanda o trâmite efetivo da ciência. E, em se tratando de trâmite efetivo, talvez nem seja o primeiro... (GERMANO, 2011).

Julgamos apenas que ele, o aspecto racional da ciência, interessa a quem vai ensinar ciências, fornecendo nuances, perspectivas, horizontes, recursos, sabores neste trabalho tão difícil que é o trabalho do ensino.

Por fim, cabe indicar sumariamente o que não cabe na discussão atual em epistemologia:

- não cabe trabalhar com a noção única de ciência, tipo A ciência; pois o trabalho científico reinventando sua própria racionalidade, diversificou-a; no interior da própria Física há Físicas, etc... Mais vale, neste ponto, sermos vagos, dizendo 'a ciência' (como equivalente de a/as), do que totalizantes ('A ciência').

- não cabe, assim, à epistemologia tentar, como porém já tentou, criar um selo de garantia e autorização, do que é e do que não é ciência, entre as diversas tentativas de constituir ciências; há várias razões, tanto intelectuais, como políticas (polêmicas), como político-intelectuais que o contraindicam... além de recairmos num enquadre que a ciência, em seu movimento intelectual de se reinventar, pode/deve precisamente fazer explodir...

- não cabe excluir de uma discussão epistemológica mais ampla todo o leque de relações entre ciência e seus efeitos na cultura, ciência e condições históricas ou políticas de produção de ciência, ciência e ética, ciência e limites éticos para a ciência, ciência e cientificismo, ciência e poder, ciência e feminismo, etc...

\section{REFERÊNCIAS BIBLIOGRÁFICAS}

ALVARADO, M.J.A. Papel de la teoría de conjuntos en la construcción de los números naturales. Paradìgma, v.27, n.1, P.32-45, 2006.

BACHELARD, G. A formação do espírito científico, Rio de Janeiro: Ed.Contraponto, 1996.

BACHELARD, G., O racionalismo aplicado. Rio de Janeiro: Zahar, 1977.

BLANCHÉ, R. La science actuelle et le rationalisme. Paris: Ed. PUF, 1967.

BLANCHÉ, R. \& DUBUCS, J. La logique et son histoire. Paris: Armand Colin, 1996. 
CARUSO, F., OGURI, V. Física Moderna: Origens Clássicas e Fundamentos Quânticos. Rio de Janeiro : Editora Campus/Elsevier, 2006.

CHÂTELET, F. Logos et praxis : recherches sur la signification théorique du marxisme. Paris: SEDES, 1972.

FOWLER, D. H. The Mathematics of Plato's Academy: A New Reconstruction. Oxford: Clarendon Press, 1987.

GERMANO, MG. Uma nova ciência para um novo senso comum. Campina Grande: EDUEPB, 2011.

GOTO, R. O cidadão Sócrates e o filosofar numa democracia. in ProPosições, v.21, n.1, P. 58-62, 2010.

KOYRÉ, A. Estudos de História do Pensamento Científico. Rio de Janeiro: Ed. Forense Universitária, 1991.

KOYRÉ, A. Estudos galilaicos. Lisboa: Publicações Dom Quixote, 1986.

MARTINET, A. Elementos de linguística geral. São Paulo: Martins Fontes, 1975.

PÉREZ, Daniel Gil \& colaboradores. Para uma visão não deformada do trabalho científico Ciência \& Educação, v.7, n.2, p.125-153, 2001.

VERNANT, J.-P. Mito e Pensamento entre os Gregos: Estudos de Psicologia

Histórica. São Paulo: Difusão Europeia do Livro, Editora da Universidade de São Paulo, 1973. 